\title{
Effects of Extended Daylength on Shoot Growth and Carbohydrate Metabolism for Creeping Bentgrass Exposed to Heat Stress
}

\author{
Qingzhang Xu, ${ }^{1}$ Bingru Huang, ${ }^{2}$ and Zhaolong Wang ${ }^{1}$ \\ Department of Plant Biology and Plant Pathology, Rutgers University, New Brunswick, NJ 08901
}

\begin{abstract}
AdDitional INDEX words. Agrostis stolonifera, high temperature, light duration
ABstract. Heat injury in creeping bentgrass (Agrostis stolonifera var. palustris Huds) has been associated with decreases in carbohydrate availability. Extending light duration may increase carbohydrate availability and thus improve growth of creeping bentgrass under heat stress. The objective of this study was to investigate whether turf performance and carbohydrate status could be improved by extending daily light duration for creeping bentgrass exposed to supraoptimal temperature conditions. 'Penncross' plants were initially grown in growth chambers set at a day/night temperature of $20 / 15{ }^{\circ} \mathrm{C}$ and 14 -hour photoperiod and then exposed to a day/night temperature of $33 / 28{ }^{\circ} \mathrm{C}$ (heat stress) and three different light durations: 14 (control), 18, and 22 hours (extended light duration) for 30 days. Turf quality and tiller density decreased with the duration of heat stress, as compared to the initial level at $20^{\circ} \mathrm{C}$, regardless of the light duration. However, both parameters increased with extended light duration from 14 to 18 or 22 hours. Extended light duration, particularly to 22 hours, also improved canopy net photosynthetic rate from -1.26 to $0.39 \mu \mathrm{mol} \cdot \mathrm{m}^{-2 \cdot} \cdot \mathrm{s}^{-1} \mathrm{and}$ daily total amount of carbon assimilation from -6.4 to $31.0 \mathrm{mmol} \cdot \mathrm{m}^{-2} \cdot \mathrm{d}^{-1}$, but reduced daily total amount of carbon loss or consumption to $50 \%$ through dark respiration compared to 14 hours treatment by the end of experiment. In addition, extending light duration from 14 to 22 hours increased water-soluble carbohydrate content in leaves both at the end of light duration and the dark period. These results demonstrated that extending light duration improved turf performance of creeping bentgrass under heat stress, as manifested by the increased tiller density and turf quality. This could be related to the increased carbohydrate production and accumulation. Supplemental lighting could be used to improve performance if creeping bentgrass is suffering from heat stress.
\end{abstract}

Carbohydrates make up the skeleton or structure of plants and are a source of metabolic energy, which is particularly important for the regrowth of shoots and roots following defoliation or mowing (Hull, 1992). Nonstructural carbohydrates are the primary energy reserves for plants exposed to stressful conditions (Beard, 1973; Howard and Watschke, 1991; Hull, 1992; Watschke et al., 1973). Research has shown that carbohydrate content decreases during heat stress, contributing to the decline in turf performance of closely-mowed cool-season grasses exposed to high temperatures (Hull, 1992; Liu and Huang, 2000, 2001; Sweeney et al., 2001; Youngner et al. 1978). The decrease in carbohydrate availability in creeping bentgrass (Agrostis stolonifera) under heat stress is related to a reduction in photosynthetic rate and an increase in dark respiration rate (Carrow, 1996; Lucas, 1996; Liu and Huang, 2001; Xu and Huang, 2000a, 2000b). Sufficient light is necessary for sustaining a level of photosynthetic activity to meet respiratory and growth demand for carbon (Turgeon, 1999). Therefore, creeping bentgrass tolerance to heat stress may be improved by increasing carbohydrate availability through maximizing photosynthetic assimilation and/or minimizing carbon consumption through dark respiration. Extending light duration or shortening the dark period on a daily basis may promote carbon production and/or reduce carbon consumption, and thus improve growth of creeping bentgrass under heat stress conditions.

Extended light durations have been found to increase dry weight accumulation, tiller production, rhizome or stolon for-

Received for publication 3 Jan. 2003. Accepted for publication 22 Sept. 2003. The authors thank the Center of Turfgrass Science, Rutgers University, for the financial support of the research. Thanks also to Jane Larkindale, Michelle Docaosta, and John Pote for reviewing the manuscript.

${ }^{1}$ Postdoctoral research associate.

${ }^{2}$ Associate professor; to whom reprints should be addressed; e-mail huang@aesop.rutgers.edu. mation, and leaf area in several grass species under optimum temperature conditions (Aamlid, 1992; Cattani, 1999; Cattani and Struik, 2001; Hay, 1990; Hay and Heide, 1983; Hay and Pedersen, 1986). Extended light duration delayed the decline in photosynthetic rate and chlorophyll content associated with foliar senescence in woody species (Rosenthal and Camm, 1997). Some studies reported increases in carbohydrate content with longer light duration (Boller and Nosberger, 1983; Hay and Pedersen, 1986; Menhenett and Wareing, 1977; Solhaug, 1991; Wang et al., 1997, 1998). Others found that light duration had no effects on carbohydrate production per day, but increased the amount of sucrose translocated out of leaves to roots (Logendra and Janes, 1992; Sicher et al., 1982). Sekizuka et al. (1995) found that increasing the light duration resulted in an increase in net carbon gain during the light period due to increases in photosynthetic rate in CAM plants. Longer light duration, however, resulted in decreased storage of total nonstructural carbohydrate (TNC) in roots of red clover (Trifolium pratense) (Jones, 1990). Studies on the effects of extended light duration on photosynthesis, respiration, and carbohydrate accumulation are limited in grass species. Available results on the effects of light duration on carbohydrate status vary with species as discussed above. Furthermore, most studies examined growth responses to different light durations for plants grown under favorable temperature conditions. Under normal temperature conditions, cool season turfgrasses growing under short daylengths typically have higher shoot density, shorter leaves, smaller shoots, and a more prostrate growth habit compared to plants under long daylength (Turgeon, 1999). However, under heat stress conditions how extended light duration may affect shoot growth, photosynthesis, dark respiration, and carbohydrate status is not well understood, particularly for creeping bentgrass maintained under frequent, low-mowing conditions.

Therefore, the objectives of this study were to investigate 
whether extending light duration could improve turf performance for creeping bentgrass exposed to heat stress, and whether the effects of changing the light duration could be related to changes in canopy net photosynthetic rate, dark respiration rate, and carbohydrate status.

\section{Materials and Methods}

Creeping bentgrass (cv. Penncross) sod was collected from a 2-year-old field plot at the Turfgrass Research Center at North Brunswick, New Jersey. Thatch was removed and 1-cm thick sod was washed free of soil and then transplanted into polyvinylchloride (PVC) tubes (10 cm in diameter and $40 \mathrm{~cm}$ in length) filled with sterilized fine silica sand in growth chambers. Turf was mowed daily at a 3 to $4 \mathrm{~mm}$ height with an electric hand clipper and fertilized twice per week with $50 \mathrm{~mL}$ full-strength Hoagland's nutrient solution per pot (a total of $12 \mathrm{~g} \mathrm{~N}$ per pot) (Hoagland and Arnon, 1950).

Plants were initially grown in growth chambers set at 20/15 ${ }^{\circ} \mathrm{C}$ (day/night) and 14-h photoperiod for $60 \mathrm{~d}$, and then exposed to a day/night temperature of $33 / 28^{\circ} \mathrm{C}$ (heat stress) with three different light durations: 14,18 , and 22 h of light during each $24-h$ cycle for $30 \mathrm{~d}$. The 14-h light duration is the average daylength during summer months in our area, which was considered as the control. The photosynthetic photon flux $(P P F)$ at the canopy level was maintained at $650 \mu \mathrm{mol} \cdot \mathrm{m}^{-2} \cdot \mathrm{s}^{-1}$, which was $\approx 70 \%$ of the light saturation point and 16 times the light compensation saturation point for $C_{3}$ plants (Salisbury and Ross, 1992). Relative humidity was $75 \%$. Plants were watered once daily until drainage was noticed from the bottom of the PVC tubes at $20 / 15^{\circ} \mathrm{C}$ and irrigated twice daily when exposed to $33 / 28^{\circ} \mathrm{C}$ and different light duration treatments.

Each light duration treatment was repeated four times in four different growth chambers (four replications). At any one time, three growth chambers were used, each for the 14-, 18-, and $22-h$ treatment. The three treatments were randomly assigned to different growth chambers. There were two subsamples in each of the four replications for each treatment. The experimental design was a randomized complete block design with repeated measures. Effects of light duration, time of light treatment, and subsamples were determined by analysis of variance according to the general linear model procedure of Statistical Analysis System (SAS, 1992). Differences among light duration treatments under heat stress and between the initial measurement $(0 \mathrm{~d})$ and different durations of heat stress for a given light duration were determined by the least significance difference (LSD) test at the 0.05 probability level.

Turf quality and tiller density were measured to evaluate effects of altering the light duration on turf performance under heat stress. Turf quality was visually rated every 3 to $5 \mathrm{~d}$ based on color, density, and uniformity on a scale of one (worst, most plants died) to nine (best, healthy and green plants). Grasses rated at six or above were considered to have acceptable quality. Tiller density was counted on intact plants nondestructively in $2 \times 2$ $\mathrm{cm}$ canopy surface areas and expressed as tiller number per unit canopy area $\left(\mathrm{cm}^{2}\right)$.

Canopy net photosynthetic rate $\left(\mathrm{P}_{\text {canopy }}\right)$ and whole-plant dark respiration rate $\left(R_{d}\right)$ were measured during the light period and the dark period, respectively, on the day before treatment $(0 \mathrm{~d}$, initial level) and at 3, 8, 15, 22, and $30 \mathrm{~d}$ of treatment using an portable gas exchange system (LI-6400; LI-COR Inc., Lincoln, Nebr). $\mathrm{P}_{\text {canopy }}$ and $\mathrm{R}_{\mathrm{d}}$ were measured by enclosing turf canopy in a transparent plexiglass chamber and an opaque chamber, respectively, fitted to the $\mathrm{CO}_{2}$ analyzer. $\mathrm{P}_{\text {canopy }}$ and $\mathrm{R}_{\mathrm{d}}$ were expressed as $\mathrm{CO}_{2}$ uptake rate and $\mathrm{CO}_{2}$ evolution rate per unit turf canopy area, respectively. Both parameters were corrected for the soil respiration rate, which was added to $\mathrm{CO}_{2}$ uptake rate for $\mathrm{P}_{\text {canopy }}$ and subtracted from $\mathrm{CO}_{2}$ evolution rate for $\mathrm{R}_{\mathrm{d}}$. However, soil respiration was minimal in the experiment because the growing medium was pure sand without organic matter and was sterilized prior to the experiment in order to minimize microbial activities. The daily total amount of carbon assimilation was estimated as canopy net photosynthetic rate $\times$ duration of light duration. The daily total amount of carbon loss or consumption was estimated using dark respiration rate $\times$ duration of dark period. Diurnal measurements of net photosynthetic rate and respiration rate showed that both rates were constant during the entire light duration or dark period in the growth chamber conditions.

Leaf samples were collected at the end of light duration and the end of dark period at 8,15,20, and $30 \mathrm{~d}$ of treatment in order to quantify the changes in water-soluble carbohydrate (WSC) levels with light duration. WSC was measured following the procedure described in Buysse and Merckx (1993). $50 \mathrm{mg}$ ground dry leaves were transferred to a tube containing $20 \mathrm{~mL}$ of water. The solution was boiled for $30 \mathrm{~min}$ and filtered into a $50 \mathrm{~mL}$ flask (filled to volume). One milliliter of solution was transferred into a glass tube. One milliliter of $18 \%$ phenol solution was then added. Five milliliters of $2 \mathrm{~N}$ sulphuric acid were rapidly added to the solution and mixed. Absorbance of the reaction solution was measured at $490 \mathrm{~nm}$ with a spectrophotometer (Genesys, Spectronic Instruments, Inc., N.Y.).

\section{Results}

Turf quality declined significantly to below the minimum acceptable value (6.0) within $10 \mathrm{~d}$ of heat stress for plants exposed to 14-h light duration and $13 \mathrm{~d}$ for the 18-h light duration (Fig. 1). Turf quality at 22-h light duration remained at or above 6.0 throughout the entire treatment period. Turf quality increased as light duration was extended from 14 to 18 and $22 \mathrm{~h}$, from $10 \mathrm{~d}$ and $7 \mathrm{~d}$ of treatment, respectively.

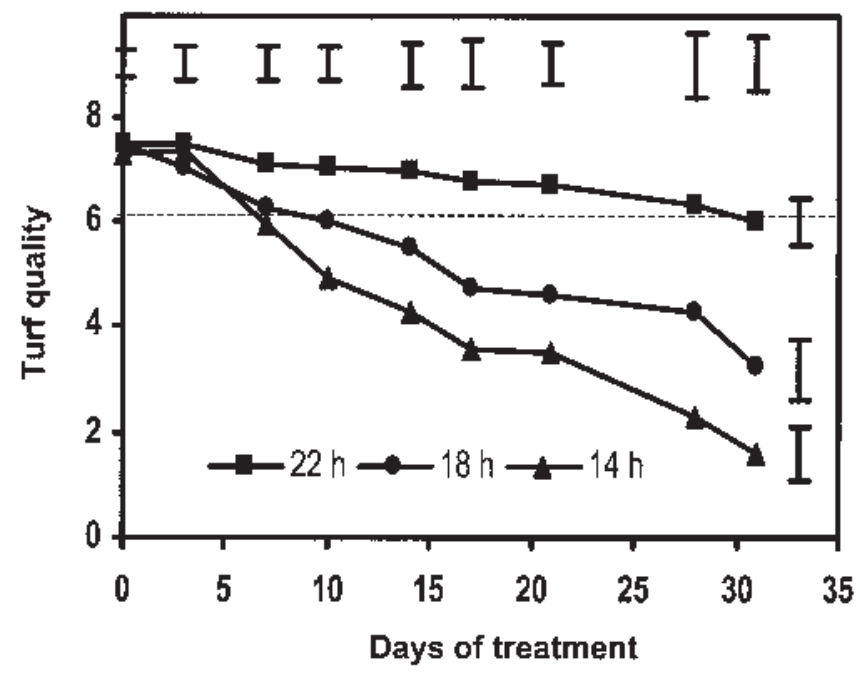

Fig. 1. Creeping bentgrass turf quality as affected by extended photoperiod and heat stress. The dotted line indicates the minimum acceptable level of turf quality (6.0). Vertical bars on the top indicate LSD values $(P=0.05)$ for treatment comparisons at a given day of treatment. Vertical bars on the right indicate LSD values $(P=0.05)$ for comparisons over time within a treatment. 


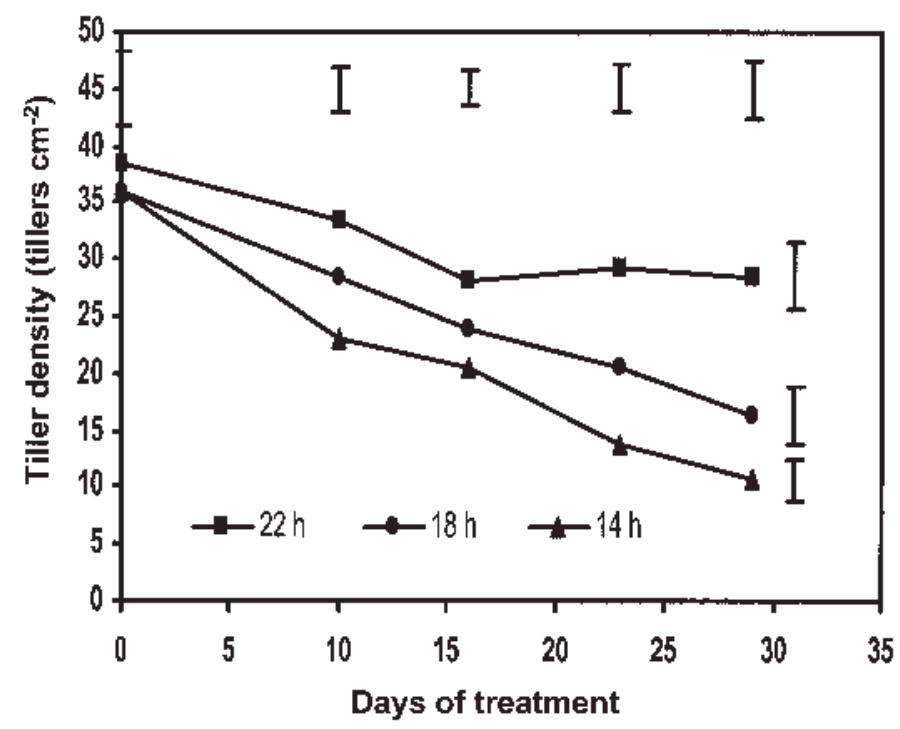

Fig. 2. Creeping bentgrass tiller density as affected by extended photoperiod and heat stress. Vertical bars on the top indicateLSD values $(P=0.05)$ for treatment comparison at a given day of treatment. Vertical bars on the right indicate LSD values $(P=0.05)$ for comparisons over time within a treatment.
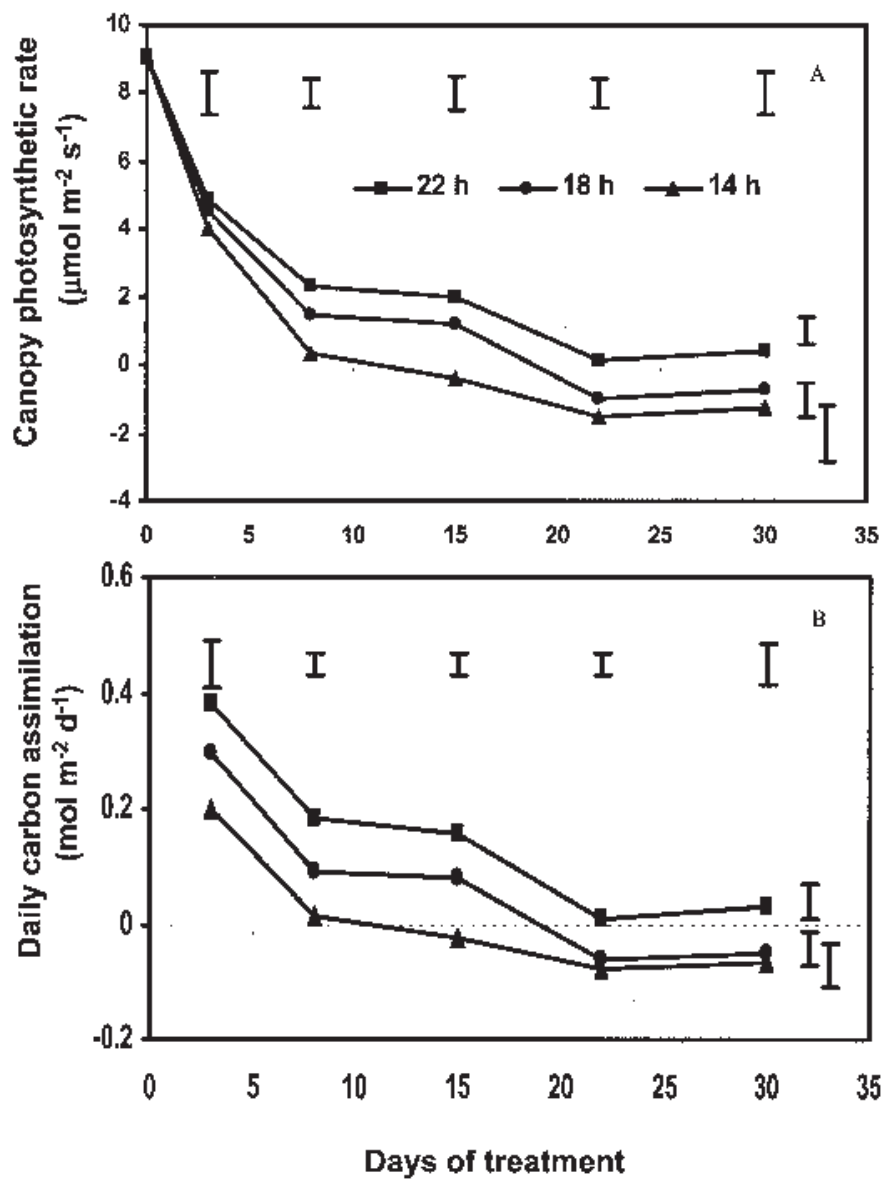

Fig. 3. Canopy net photosynthetic rate (A) and daily total carbon assimilation (B) as affected by extended photoperiod for creeping bentgrass exposed to heat stress. Vertical bars on the top indicate LSD values $(P=0.05)$ for treatment comparison at a given day of treatment. Vertical bars on the right indicate LSD values $(P=0.05)$ comparisons over time within a treatment.
Tiller density decreased with the duration of heat stress in all three light duration treatments (Fig. 2). The decline was more rapid at a 14- and 18-h than that at a 22-h light duration. Tiller density was highest at 22-h light duration and lowest at 14-h light duration during the entire treatment period.

Rapid decline in canopy net photosynthetic rate $\left(\mathrm{P}_{\text {canopy }}\right)$ (Fig. 3A) and daily total amount of carbon assimilation (Fig. 3B) occurred with the duration of heat stress in all three light duration treatments (Fig. 3A). $\mathrm{P}_{\text {canopy }}$ and daily carbon assimilation dropped below 0 at 15 and $22 \mathrm{~d}$ of 14 - and 18 -h light duration, respectively. Plants grown at 22-h light duration maintained a positive $\mathrm{P}_{\text {canopy }}$ and daily carbon assimilation during most of the experimental period. $\mathrm{P}_{\text {canopy }}$ was higher than that at 14 -h light duration at 8 , 15,22 , and $30 \mathrm{~d}$ for plants exposed to 22 -h light duration and at 8 and $15 \mathrm{~d}$ for plants exposed to 18-h light duration (Fig. 3A). Daily total carbon assimilation was significantly higher throughout the entire treatment period at 22-h light duration and at 3,8 and $15 \mathrm{~d}$ at 18 -h light duration, as compared to that at 14-h light duration (Fig. 3B).

Whole-plant dark respiration rate $\left(\mathrm{R}_{\mathrm{d}}\right)$ at 22-h light duration was higher than that at 14- and 18-h light duration from 8 to 30 $\mathrm{d}$ of treatment (Fig. 4A). No significant differences in $R_{d}$ were found between 14- and 18-h light durations. Daily total amount of carbon loss or consumption due to respiration was lowest at 22-h light duration, intermediate at 18-h light duration, and
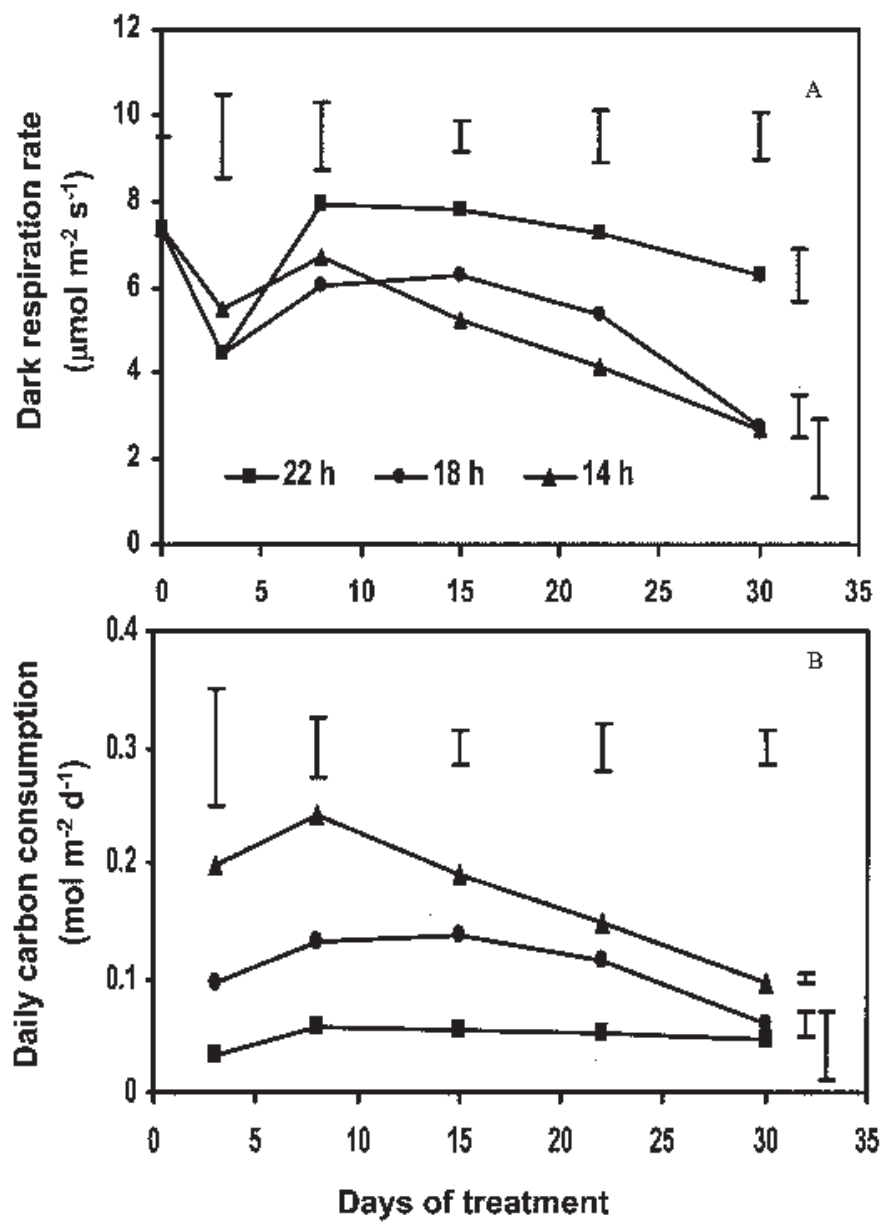

Fig. 4. Whole-plant dark respiration rate (A) and daily total amount of carbon loss or consumption $(\mathbf{B})$ as affected by extended photoperiod for creeping bentgrass exposed to heat stress. Vertical bars on the top indicate LSD values $(P=0.05)$ for treatment comparison at a given day of treatment. Vertical bars on the right indicate LSD values $(P=0.05)$ for comparisons over time within a treatment. 
Table 1. Water-soluble carbohydrate content at the end of photoperiod (EOP) and the end of the dark period (EOD) on 7, 14, 20, and 29 d of heat stress. LSD values $(P=0.05)$ on the bottom of the table are for treatment comparison at a given day of treatment. LSD values $(P=0.05)$ on right of the table are for comparisons over time within a treatment.

\begin{tabular}{|c|c|c|c|c|c|c|c|c|c|}
\hline \multicolumn{10}{|c|}{ Heat stress duration (d) } \\
\hline & \multicolumn{2}{|c|}{7} & \multicolumn{2}{|c|}{14} & \multicolumn{2}{|c|}{20} & \multicolumn{2}{|c|}{29} & \multirow[b]{2}{*}{ LSD } \\
\hline & EOP & $\overline{\text { EOD }}$ & EOP & $\overline{\mathrm{EOD}}$ & EOP & $\overline{\text { EOD }}$ & EOP & $\overline{\text { EOD }}$ & \\
\hline $22 \mathrm{~h}$ & 52.4 & 54.0 & 53.4 & 58.3 & 57.1 & 58.0 & 63.7 & 56.2 & 2.98 \\
\hline $18 \mathrm{~h}$ & 48.8 & 36.2 & 53.8 & 47.3 & 55.0 & 45.2 & 57.0 & 47.0 & 2.40 \\
\hline $14 \mathrm{~h}$ & 57.0 & 38.1 & 64.3 & 39.9 & 45.0 & 37.9 & 43.0 & 31.2 & 3.70 \\
\hline LSD & 2.37 & 1.89 & 2.80 & 5.00 & 4.10 & 3.10 & 5.00 & 5.50 & \\
\hline
\end{tabular}

highest at 14-h light duration during most of the experimental period (Fig. 4B).

Water-soluble carbohydrate (WSC) content for plants exposed to 14- or 18-h light duration decreased significantly during the 10 or 6-h dark period (from the end of the light duration to the end of the dark period) on all measurement dates throughout the experimental period (Table 1). A decrease in WSC during the dark period occurred only at $29 \mathrm{~d}$ of treatment for plants exposed to 22 -h light duration. Plants at 22-h light duration maintained higher WSC than those at 14-h light duration at the end of dark period on most days of the treatment period. WSC content at the end of light duration was significantly higher at 18 - or 22-h light duration than that at 14-h light duration at 14,20 , and $29 \mathrm{~d}$ of treatment.

\section{Discussion}

Previous studies reported that prolonging light duration resulted in increases in leaf growth rate, tiller production, and dry matter accumulation in several grass species under favorable temperature conditions (Aamlid, 1992; Cattani, 1999; Hay and Heide, 1983; Hay and Petersen, 1986). Our study demonstrated that extending the light duration, particularly from the average summer daylength of 14 to $22 \mathrm{~h}$, significantly improved turf quality and tiller density during heat stress. These results indicate that extending light duration could help alleviate heat stress injury or summer decline in creeping bentgrass.

Improved turf performance associated with extended light duration was related to increases in water-soluble carbohydrate content. There was a higher WSC content at the end of the dark period during a 24-h period with light durations of 18 or $22 \mathrm{~h}$ compared to that of $14 \mathrm{~h}$. This result suggested that prolonging the light duration or shortening the dark period favored carbohydrate accumulation. Similar results were found in apple tree (Malus domestica Borhk) (Wang et al., 1997) and white clover (Trifolium repens L.) (Boller and Nosberger, 1983). Concentrations of glucose, fructose, sorbitol, and starch in leaves of apple tree increased with light duration (Wang et al., 1997). Total nonstructural carbohydrate content increased in leaves, petioles, stolons, and roots in white clover as light duration increased from 12 to $16 \mathrm{~h}$ (Boller and Nosberger, 1983). Although daylength did not influence the concentration of reducing sugars, nonreducing sugars, starch, and TNC in taproots of Onobrychis viciifolia Scop (Kallenbach et al.1995), however, plant height was stimulated by long days. Solhaug (1991) also reported that more carbon assimilates were allocated to shoot growth instead of increase in sugar concentration (especially to leaf growth in Kentucky bluegrass) as daylength increased, which is believed to be responsible for increased dry matter production with increasing light duration.

The increases in carbohydrate content with extended light duration could be due to the increase in daily carbon assimilation (Fig. 3B) in companion with the reduction in daily carbon loss or consumption through dark respiration (Fig. 4B) in creeping bentgrass. Daily total carbon assimilation was $\approx 2$-fold higher in plants subjected to 22-h light duration as compared to those exposed to 14-h light duration and corresponding carbon consumption was about this magnitude lower. Increased net carbon gain during the light period with increasing daylength has been reported in CAM plants, which was attributed to increases in photosynthetic rate (Sekizuka et al., 1995). Others also reported increases in net photosynthetic rate with prolonging light duration (Hay and Heide, 1983; Heide et al. 1985; Jones, 1990; Walsh et al., 1987). Aamlid (1992), however, reported that net assimilation rate per unit leaf area did not change with increases in the light duration in Kentucky bluegrass. Single-leaf net photosynthetic rate was not evaluated in our study. The higher canopy net photosynthetic rates observed in this study (Fig. 3A) were probably related to higher tiller density which contributed to greater leaf area (Fig. 2 ). Tiller density of plants exposed to 18 - or 22-h photoperiod was significantly higher than plants growing at the 14-h natural daylength.

In summary, although exposing creeping bentgrass to heat stress decreased turf quality, extending the light duration improved turf quality and tiller production. The effectiveness of extended light duration increased with the duration of treatment. Less dramatic results may occur at shorter light durations than those used in this study. The improved turf performance by extending light duration under heat stress could be associated with increased carbohydrate content in creeping bentgrass leaves, which appeared to be the result of an increase in daily carbon production and a reduction in daily carbon consumption.

\section{Literature Cited}

Aamlid, T.S. 1992. Effects of temperature and light duration on growth and development of tillers and rhizomes in Poa pratensis L. ecotypes. Ann. Bot. 69:289-296.

Beard, J.B. 1973. Turfgrass: Science and culture. Prentice-Hall, Englewood Cliffs, N.J.

Boller, C. and J. Nosberger. 1983. Effects of temperature and photoperiod on stolon characteristics, dry matter partitioning, and nonstructural carbohydrate concentration of two white clover ecotypes. Crop Sci. 23:1057-1062.

Buysse, J., and R. Merckx. 1993. An improved colorimetric method to quantify sugar content in plant tissue. J. Expt. Bot. 44:1627-1629.

Carrow, R.N. 1996. Summer decline of bentgrass greens. Golf Course Mgt. 64:51-56.

Cattani, D.J. 1999. Early plant development in 'Emerald' and 'UM67-10' creeping bentgrass. Crop Sci. 39:754-762.

Cattani, D.J. and P.C. Struik. 2001. Tillering, internode development, and dry matter partitioning in creeping bentgrass. Crop Sci. 41:111-118.

Hay, R.K.M. 1990. The influence of photoperiod on dry-matter production of grasses and cereals. New Phytol. 116:233-254.

Hay, R.K.M. and K. Pedersen. 1986. Influence of long photoperiod on the growth of timothy (Phleum pratense L.) varieties from different 
latitudes in northern Europe. Grass Forage Sci. 41:311-317.

Hay, R.K.M. and O.M. Heide. 1983. Specific photoperiodic stimulation of dry matter production in a high-latitude cultivar of Poa pratensis. Physiol. Plant. 57:135-142.

Heide, O.M., M.G. Bush, and L.T. Evans. 1985. Interaction of photoperiod and gibberellin on growth and photosynthesis of high-latitude Poa pratensis. Physiol. Plant. 65:135-145.

Hoagland, D.R. and D.I. Arnon. 1950. The water-culture method for growing plants without soil. Calif. Agr. Expt. Sta. Circ. 347.

Howard, H.F. and T.L. Watschke. 1991. Variable high-temperature tolerance among Kentucky bluegrass cultivars. Agron. J. 83:69-693.

Hull, R. 1992. Energy relations and carbohydrate partitioning in turfgrass, p. 175-205. In: D.V. Waddington, R.N. Carrow, and R.C. Sherman. (eds.). Turfgrass. Amer. Soc. Agron., Madison, Wis.

Jones, T.W.A. 1990. Use of flowering mutant to investigate changes in carbohydrates during floral transition in red clover. J. Expt. Bot. 41: 1013-1019.

Kallenbach, R.L., A.G. Matches, and J.R. Mahan. 1995. Daylength influence on the growth and metabolism of sainfoin. Crop Sci. 35: 831-835.

Liu, X. and B. Huang. 2000. Carbohydrate accumulation in relation to heat stress tolerance in two creeping bentgrass cultivars. J. Amer. Soc. Hort. Sci. 125:442-447.

Liu, X. and B. Huang. 2001. Seasonal changes and cultivars difference in turf quality, photosynthesis, and respiration of creeping bentgrass. HortScience 36:1131-1135.

Logendra, S. and H.W. Janes. 1992. Light duration effects on carbon partitioning and translocation in tomato. Scientia Hort. 52:19-25.

Lucas, L.T. 1996. Heat stress and decline of creeping bentgrass. Turfgrass Trends. 5(7):1-8.

Menhenett, R. and P.F. Wareing. 1977. Effects of photoperiod and temperature on the growth and cytokinin content of two populations of Dactylis glomerata (Cocksfoot). New Phytol. 8:17-25.

Rosenthal, S.I. and E.L. Camm. 1997. Photosynthetic decline and pigment loss during autumn foliar senescence in western larch (Larix occidentalis). Tree Physiol. 17:767-775.

Salisbury, F.B. and C.W. Ross. 1992. Plant physiology, p. 254-256. Wadsworth Publ., Belmont, Calif.

Sekizuka, F., A. Nose, Y. Kawamitsu, S. Murayama, and K.I. Arisumi.
1995. Effects of day length on gas exchange characteristics in the Crassulacean acid metabolism plant Dendrobium ekapol cv. Panda. Jpn. J. Crop Sci. 64:201-208.

SAS Institute. 1992. Fundamentals of the SAS system (version 6). SAS Inst., Cary, N.C.

Sicher, R.C., W.G. Kremer, and N.J. Chatterton. 1982. Effects of shortened day length upon translocation and starch accumulation by maize, wheat, and Pamgola grass leaves. Can. J. Bot. 60:1304-1309.

Solhaug, K.A. 1991.Effects of photoperiod and temperature on sugars and fructans in leaf blades, leaf sheaths and stem, and roots in relation to growth of Poa pratensis. Physiol. Plant. 82:171-178.

Sweeney, P., K. Danneberger, D. Wang, and M. McBride. 2001. Root weight, nonstructural carbohydrate content, and shoot density of highdensity creeping bentgrass cultivars. HortScience 36:368-370.

Turgeon, A.J. 1999. Turfgrass management. Prentice Hall, Upper Saddle River, N.J.

Walsh, K.B., J.K. Wessey, and D.B. Layzell. 1987. Carbohydrate supply and $\mathrm{N}_{2}$ Fixation in soybean: the effect of varied daylength and stem girdling. Plant Physiol. 85:137-144.

Wang, Z., Z. Yuan, and B. Quebeddeaux. 1997. Photoperiod alters diurnal carbon partitioning into sorbitol and other carbohydrates in apple. Austral. J. Plant Physiol. 24:587-597.

Wang, Z., Z. Yuan, and B. Quebeddeaux. 1998. Photoperiod alters partitioning of newly-fixed ${ }^{14} \mathrm{C}$ and reserve carbon into sorbitol, sucrose and starch in apple leaves, stems, and roots. Austral. J. Plant Physiol. 25:503-506.

Watschke, T.L., R.L. Schmidt, E.W. Carson, and R.E. Blaser. 1973. Temperature influence on the physiology of selected cool season turfgrasses and bermudagrass. Crop Sci. 13:591-594.

$\mathrm{Xu}$, Q. and B. Huang. 2000a. Growth and physiological responses of creeping bentgrass to changes in air and soil temperatures. Crop Sci. 40:1363-1368.

Xu, Q. and B. Huang. 2000b. Effects of differential air and soil temperature on carbohydrate metabolism in creeping bentgrass. Crop Sci. 40:1368-1374.

Youngner, V.B., F.J. Nudge, and S. Spaulding. 1978. Seasonal changes in nonstructural carbohydrate levels and innovation number of Kentucky bluegrass turf growing in three plant-climate areas. Agron. J. 70:407-411. 